\title{
Indirect Contact Transmission Infection
}

National Cancer Institute

\section{Source}

National Cancer Institute. Indirect Contact Transmission Infection. NCI Thesaurus. Code C50612.

Infection transmitted by water, food or other means of conveyance. 